\title{
Clinical Study \\ Penetrating Neck Trauma in a Level II Trauma Hospital, Saudi Arabia
}

\author{
Wagih Mommtaz Ghnnam, ${ }^{1}$ Ali Saeed Al-Mastour, ${ }^{2}$ and Mohamed Fayez Bazeed ${ }^{3}$ \\ ${ }^{1}$ General Surgery Department, Mansoura Faculty of Medicine, Mansoura University, Mansoura 35116, Egypt \\ ${ }^{2}$ Head and Neck Surgery, Khamis Mushayt General Hospital, Khamis Mushayt Asceer Area, Saudi Arabia \\ ${ }^{3}$ Radiology Department, Mansoura Faculty of Medicine, Mansoura University, Mansoura, Egypt \\ Correspondence should be addressed to Wagih Mommtaz Ghnnam,wghnnam@gmail.com
}

Received 8 August 2011; Accepted 13 September 2011

Academic Editors: F. Lateef and J. H. H. Yeung

Copyright (C 2012 Wagih Mommtaz Ghnnam et al. This is an open access article distributed under the Creative Commons Attribution License, which permits unrestricted use, distribution, and reproduction in any medium, provided the original work is properly cited.

\begin{abstract}
Background. Penetrating neck trauma is a unique form of trauma that is on the rise all over the world and contributes significantly to high morbidity and mortality. Design. Retrospective and prospective case series. Setting. Urban, level II trauma hospital. Patients. Patients who had sustained penetrating trauma to the neck. Main Outcome Measures. The aim of this study was to evaluate the incidence, injury characteristics, and treatment outcome of penetrating neck trauma in our local setting and to suggest treatment protocols. Patients and Methods. This was a combined retrospective and prospective study of penetrating neck trauma patients who were managed at level II trauma hospital, Asceer region, Saudi Arabia, from March 2008 to March 2011. Results. A total of 49 patients were studied. Males outnumbered females by a ratio of 11.25:1. Their mean age (SD) was 31.1(12.6) years. Fourteen patients were caused by stab-wound injuries. Most injuries were in zone II (83.7\%). More than one-third of patients were treated conservatively. Wound exploration and debridement were the mode of treatment in the majority of cases. The mean duration of hospital stay was 6.6 days (1-18 days). Mortality rate was $12.2 \%$. Conclusion. The present paper illustrates the difficulties of managing penetrating neck injuries in our region, Saudi Arabia.
\end{abstract}

\section{Introduction}

Injuries to the neck are most commonly associated with motor vehicle crashes. Other mechanisms include gunshot, assaults, hangings, shrapnels, and falls [1]. Penetrating injuries to the neck may appear benign based on the appearance of the wound, but because of the number and variety of vital structure in a small anatomic region, the potential for underlying organ injury is significant [2].

The etiology of penetrating neck injuries are numerous, the most common of which are gunshots, stabbings, and miscellaneous. Each category has different predisposing factors and injury patterns. Gunshot wounds and other highvelocity injuries do more damage and thus are more likely to require surgical exploration. The miscellaneous category represents a broad spectrum of injury by various other penetrating objects from automobile glass secondary to car accidents to impalement from airborne objects. Associated injury patterns can be as broad and unpredictable as the mechanism of injury itself [3].

The neck is divided into three zones for the management of penetrating trauma: Zone I extends from the sternal notch to the cricoid cartilage. Injuries to zone I have the highest mortality due to associated injuries to intrathoracic structures. Zone II lies between the cricoid cartilage and the angle of the mandible. Zone II injuries are the most common. Zone III consists of the upper neck above the angle of the mandible to the base of the skull [4]. Surgical exposure is difficult in zones I and III. Isolated penetrating neck injuries are uncommon. Penetrating neck injuries occur most often in the setting of multiple traumas. The presentation may range from relatively asymptomatic to dramatic and acutely lifethreatening state depending upon the structures involved. To avoid missing subtle findings, the search for injuries must be systematic. The history and physical examination should be 
directed to the areas of potential injury including vascular, laryngotracheal, esophageal, and neurological injuries [5].

Exsanguination is the most common cause of immediate death after a vascular injury. Morbidity and mortality also result from hematomas compromising the airway, direct vascular injury with subsequent occlusion, Mortality from these injuries ranges from $5 \%$ to $50 \%$ [6]. The clinical features of a vascular injury may be quite obvious, such as pulsatile bleeding or an expanding hematoma. These signs, believed to demonstrate a definite vascular injury, are referred to as "hard signs" [7]. Vascular injuries also may present with subtle neurologic or pulse deficits, therefore, a rapid examination is necessary. Late complications include traumatic aneurysm and arteriovenous fistula [8].

Laryngotracheal injuries complicate $10 \%$ of penetrating neck injuries. With penetrating trauma, these injuries are rarely occult. The most common signs and symptoms include dyspnea, stridor, dysphonia, hemoptysis, laryngeal tenderness, subcutaneous emphysema, and air bubbling from the wound. Any of the above findings mandate laryngoscopy [9].

Esophageal injury occurs less frequently than vascular or laryngotracheal injuries due to the relatively protected location of the esophagus [10]. Some authors have noted dyspnea, hemoptysis, and air-bubbling through wounds as "hard signs" of aerodigestive tract injuries [7]. Most esophageal injuries are associated with laryngotracheal injuries due to its location. Signs and symptoms of esophageal injury include dysphagia, oropharyngeal hemorrhage, nasogastric tube bleeding, subcutaneous emphysema, and resistance to movement of the neck [10]. As with laryngotracheal injuries, crepitance is a strong indicator of esophageal injury. Despite these signs, esophageal injuries are the most commonly missed injuries in the neck. A delay in the diagnosis of these injuries increases mortality. An early diagnosis is required to prevent the development of mediastinitis due to paraesophageal contamination [10].

Injuries to the nervous system include direct spinal cord injury, cranial nerve injury, peripheral nerve injury, and deficits in the central nervous system. Approximately $10 \%$ of patients with penetrating neck trauma will have an associated spinal cord or brachial plexus injury [11]. The clinical presentation will depend upon the involved structure and the extent of the injury. Also the presence of a peripheral nerve injury should alert the evaluating personnel to the possibility of an associated arterial injury because most nerves are located close to large arteries [6].

The successful management of penetrating trauma relies on rapid diagnosis and prompt intervention. Injuries must be detected, and control achieved, without delay. There should be no unnecessary investigations and no unnecessary interventions. Clinical examination is, in general, more reliable in penetrating than in blunt trauma. Many injury patterns can be fully assessed clinically, without any need for radiological or other assessment. Clinical assessment is vital to this process, to direct the right investigation to the right patient at the right time [12]. Many injuries can now be managed entirely nonoperatively. This avoids the complications of surgery and anaesthesia, and improves hospital efficiency. Decision-making focuses on the presence of clinical signs and symptoms, rather than penetration of the platysma muscle. No shock, no expanding hematoma, no evolving stroke, no pain on swallowing, no haemoptysis, no subcutaneous emphysema, nor neurological deficit in favor of nonoperative management [13].

The aim of this study was to assess the incidence, causative factors, management, and outcome of patients with penetrating neck wounds, seen at a level II trauma hospital in Saudi arabia.

\section{Patients and Methods}

This was a three-year combined retrospective and prospective study of penetrating neck injuries patients that presented to our hospital between March 2008 and March 2011. The details of patients who presented from March 2008 to March 2009 were retrieved retrospectively from patient registers kept in the Medical record departments, the surgical wards, and operating theatre. Patients who presented to the A and E department between April 2009 and March 2011 were prospectively enrolled in the study. Patients with incomplete data and those who were brought in dead were excluded from this study. Ethical approval to conduct the study was obtained from our hospital ethics review committee before the commencement of the study. All recruited patients were first resuscitated in the emergency department according to advanced trauma life support (ATLS) guidelines. From the emergency department, patients with hard signs mandate exploration were taken into the operative theatre immediately. patients with penetrating neck trauma with no signs mandate immediate exploration were admitted to surgical wards or the intensive care unit (ICU) from where further treatment was instituted and necessary investigations were completed. The information gathered from patients included demographic data, zone of injury, type of injury, treatment modalities, and outcome measures (i.e., length of hospital stay, complications, and mortality). Data were analyzed using SPSS computer software version 19. A $P$ value of 0.05 was considered statistically significant.

\section{Results}

During the period of study, a total of 49 patients with penetrating neck trauma were admitted to our surgical department. There were 45 male patients (91.8\%) in the study. Age ranged from 16 to 68 years; the mean age (SD) was 31.1 (12.6) years. The main causes of penetrating neck injury were road traffic accidents wounds in 26 cases (53\%), and stab wounds, 14 cases $(28.6 \%)$. The most frequently involved area was zone II 41 cases $(83.7 \%)$, followed by zone I 5 cases (10.2\%), and zone III three cases $(6.1 \%$; Table 1). In this study, six patients died giving a mortality rate of $12.2 \%$. There were 13 cases $(26.5 \%)$ of hemodynamic instability. The mean hospital stay was $6.8 \pm 3.4$ days ( 1 to 18 days). The main indication for surgical exploration was profuse hemorrhage and shock in 9 cases $(18.4 \%)$, followed by subcutaneous emphysema in 6 cases $(12.2 \%)$ and expanding hematoma also in 3 cases $(6.1 \%)$. The most 
TABLE 1: demographic data of the studied patients.

\begin{tabular}{|c|c|c|c|c|}
\hline Variable & Group I (living $n=43$ ) & Group II (died $n=6)$ & Total $(n=49)$ & $P$ value \\
\hline Mean age (SD; years) & $32(13)$ & $24.8(7.6)$ & $31.1(12.6)$ & 0.19 \\
\hline Range (years) & $(17-68)$ & $(18-37)$ & $(17-68)$ & \\
\hline \multicolumn{5}{|l|}{ Sex } \\
\hline Males (\%) & $40(93)$ & $5(83.3)$ & $45(91.8)$ & 0.41 \\
\hline Females (\%) & $3(7)$ & $1(16.7)$ & $4(8.2)$ & 0.98 \\
\hline \multicolumn{5}{|l|}{ Cause of injury } \\
\hline Road traffic accident & $24(55.8)$ & $2(33.3)$ & $26(53)$ & 0.54 \\
\hline Stab wound & $11(25.6)$ & $3(50)$ & $14(28.6)$ & 0.45 \\
\hline Gun shot & $4(9.3)$ & $1(16.7)$ & $5(10.2)$ & 0.87 \\
\hline Shrapnels & $4(9.3)$ & 0 & $4(8.2)$ & 0.98 \\
\hline \multicolumn{5}{|l|}{ Zone injured } \\
\hline Zone I & $2(4.7)$ & $3(50)$ & $5(10.2)$ & 0.04 \\
\hline Zone II & $39(90.7)$ & $2(33.3)$ & $41(83.7)$ & 0.002 \\
\hline Zone III & $2(4.6)$ & $1(16.7)$ & $3(6.1)$ & 0.7 \\
\hline Operative cases & $20(46.5)$ & $1(16.7)$ & $21(42.9)$ & 0.34 \\
\hline Nonoperative & $23(53.5)$ & $5(83.3)$ & $28(57.1)$ & 0.34 \\
\hline
\end{tabular}

TABLE 2: Hospital stay, incidence of surgical exploration, and injured structures in both groups.

\begin{tabular}{lccc}
\hline Parameter & Group I (living $n=43)$ & Group II (died $n=6)$ & Total $(n=49)$ \\
\hline Hospital stay mean (SD; days) & $6.6(3.4)$ & $2(1)$ & $6.6(3.4)$ \\
Range (days) & $1-18$ & $1-3$ & $1-18$ \\
\hline Indication of surgical exploration & & & 0.002 \\
$\quad$ Profuse hemorrhage and shock & $9(21)$ & 0 & $9(18.4)$ \\
Subcutaneous emphysema & $5(11.6)$ & $1(16.7)$ & $6(12.2)$ \\
Expanding hematoma & $2(4.7)$ & $1(16.7)$ & $3(6.1)$ \\
Foreign body (FB) removal & $3(7)$ & 0 & $3(6.1)$ \\
\hline Injured structure (\%) & & 0 & $23(46.9)$ \\
Soft tissue & $23(50)$ & $1(16.7)$ & $5(10.2)$ \\
Arterial & $4(9.3)$ & 0 & $10(20.4)$ \\
Venous & $10(23.3)$ & 0 & $3(6.1)$ \\
Larynx and trachea & $3(7)$ & 0 & $2(4.1)$ \\
Pharynx and esophagus & $2(4.7)$ & $1(16.7)$ & $2(4.1)$ \\
Spine and neurologic & $1(2.3)$ & $4(66.7)$ & $4(8.1)$ \\
$\quad$ Combined vascular and & 0 & & NA \\
aerodigestive & & 0 & \\
\hline
\end{tabular}

commonly affected anatomical structures were the neck veins (24.5\%), followed by neck arteries (10.2\%), and the larynx and trachea (6.1\%; Table 2). Surgery consisted of vascular ligatures in 12 cases $(24.5 \%)$; the jugular veins were the most frequently involved (Figure 3). Laryngeal and tracheal suture was done in 3 cases $(6.1 \%)$. Forty-three patients $(87.8 \%)$ survived. The mean age of survivors was higher (32.2 years) than that of nonsurvivors (Table 3 ).

\section{Discussion}

Penetrating neck wounds complicate approximately $10 \%$ of all trauma presentations [1]. While they are most commonly associated with violent acts, they are also encountered in road traffic collisions and other accidents in our study it represent about $2.3 \%$ of all trauma registers during the study period. Males predominated in this study (45 cases, $91.8 \%$ ); the mean age was 31 years (16 to 68 years). Other series have also reported a predominance of males, ranging from 71 to $91 \%$, and mean ages ranging from 25 to 34.5 years $[1,7,13,14]$. Etiologically, there were 26 cases of road traffic accidents (RTA) wounds (53\%) because RTA are frequent in our locality, followed by 14 cases of knife wounds (28.6\%). In this regard, the literature presents a variety of percentages, with the rate of knife wounds ranging from 20.7 to $95.7 \%$ [15]. The most frequently affected region in our study was 
TABLE 3: Type of surgery and postoperative complications in the studied patients.

\begin{tabular}{lccc}
\hline Complications & Group I (living $n=43)$ & Group II $($ died $n=6)$ & \\
\hline Type of surgery (\%) & & $1(16.7)$ & $5(10.2)$ \\
$\quad$ Arterial ligature & $4(9.3)$ & 0 & $10(20.4)$ \\
Vein ligature & $10(23.3)$ & $1(16.7)$ & $3(6.1)$ \\
Larynx and tracheal suture & $2(4.7)$ & $1(16.7)$ & $2(4.1)$ \\
Pharynx and esophagus suture & $1(2.3)$ & 0 & $3(6.1)$ \\
FB removal & $3(7)$ & 0 & $4(8.1)$ \\
\hline Wound sepsis (\%) & $4(9.3)$ & 0 & $2(4.1)$ \\
\hline Hoarseness (\%) & $2(4.7)$ & 0 & 0 \\
\hline Arteriovenous fistula & 0 & 0
\end{tabular}

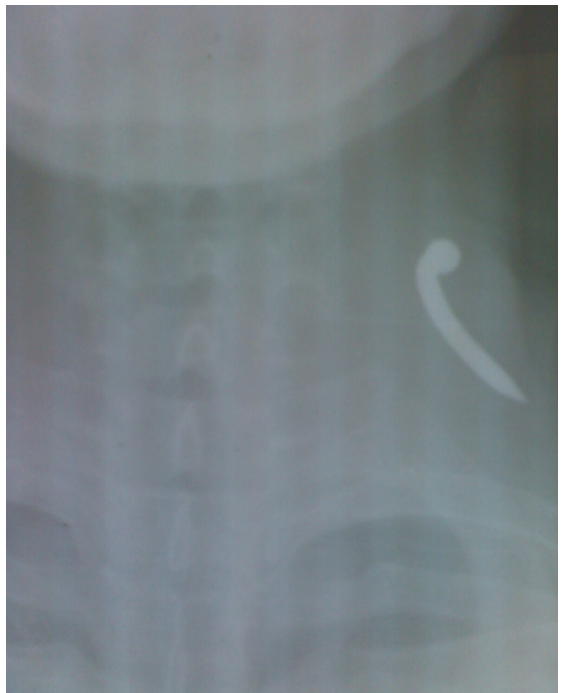

(a)

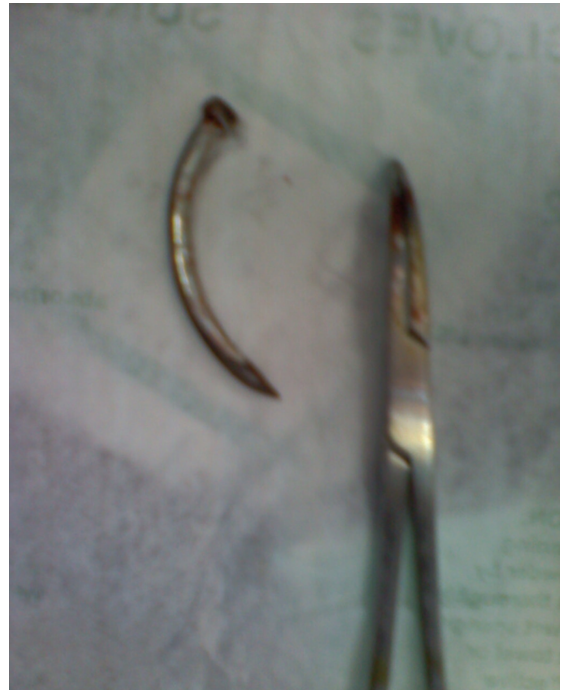

(b)

FIgURE 1: Penetrating foreign body (nail) in the neck X-ray neck and its size after extraction.

zone II ( 41 cases, $83.7 \%$ ), followed by zone I ( 5 cases, $10.2 \%$ ), and zone III ( 3 case, $6.1 \%$ ). In the literature, zone II is also the most frequently affected site ( 59 to $82 \%$ ), followed by zone I (5 to $25 \%$ ), and zone III (2 to $25 \%$ ) [1, 7, 14-16].

Diagnostic evaluation of penetrating neck injuries in patients who do not require immediate surgical intervention is challenging because of the multiple vital structures contained within this anatomic region. Patients who have definite signs of arterial injuries or are hemodynamically unstable are taken to surgery with no further imaging procedures $[16,17]$. In our study for patients suspected of having arterial injuries without compromise of their vital signs, CT with IV contrast of the neck and upper chest was performed. In the literature: several strategies for diagnosis and management may be considered. Physical examination alone has low sensitivity for detection of vascular injuries $[2,15,17]$. Routine surgical therapy is no longer performed in all patients with wounds that penetrate the platysma because of the high attendant morbidity (26\%) and the high proportion of negative exploration results (as high as $51 \%$ )
[18-20]. In our study we followed the selective approach of management, indications of immediate surgical exploration included profuse haemorrhage and shock in 9 cases (18.4\%), subcutaneous emphysema in 6 cases $(12.2 \%)$ expanding haematoma in 3 (6.1\% cases), and foreign body removal in 3 cases (6.1\%; Figures 1(a) and 1(b)).

There are clear indications for emergency operative intervention which have remained unchanged. As a rule, nonoperative management should never be done on a patient who is hemodynamically unstable. Also, adequate airway, ventilation, resuscitation, and determination of any severe neurologic deficit are essential in the optimal management of any injured patient.

In general, a more selective approach is taken for Zones I and III, because of the inherent difficulty in examining and operatively exposing these areas [6]. For example, a penetrating Zone I injury might necessitate a thoracotomy (median sternotomy or anterolateral approach) to optimally manage a vascular injury. Also, disarticulation of the mandible, resection of the angle of the mandible, resection of 
the styloid, or other maneuvers may be required in order to obtain adequate exposure with Zone III penetrating injuries $[13,19,20]$.

The paramount controversy centers around those patients who present hemodynamically stable, with penetrating neck wounds in Zone II and no findings suggestive of a vital structure injury. While many factors must be considered and each case should be individualized, there is an ongoing debate over how this particular subset of patients should be managed. In the past, there have been two basic management options for penetrating Zone II injuries: (1) mandatory operative intervention for any injury which penetrates the platysma and (2) selective management which involves panendoscopy (laryngoscopy, tracheoscopy, bronchoscopy, and esophagoscopy), esophagography, and arteriography. With the selective approach, if a vital structure is noted to be injured, neck exploration is performed. Although each decision should be based on the resources of the hospital, the experience of the surgeon, and the compliance and cooperation of the patient, selective management of Zone II injuries is the approach of choice in most tertiary medical centers today $[16,20-22]$. In our study we followed the selective approach with individualization of each case and we get comparable favourable results with the literatures. Inevitably vascular injury is the most frequent complication of penetrating neck trauma, occurring in one-quarter of all cases, and carrying amortality of nearly $50 \%$ [22]. Trauma to the trachea occurs in one-tenth of cases, and mortality in these cases approaches 20\% [23]. Other structures at risk of damage include the oesophagus, which can cause leakage of digestive enzymes and bacteria into surrounding tissues. Extensive penetration may result in oropharyngeal trauma. Currently it is thought that penetrating neck injuries carry a 3-6\% mortality rate [22]. The mortality rate for Zone II stable injuries is generally perceived to be lower than this, although there are no large studies to back this up. Penetrating Zone II neck trauma found that selective operative management and mandatory exploration of penetrating injuries to Zone II had similar diagnostic accuracy, therefore selective management is recommended to avoid unnecessary operations $[22,24]$. Stable patients without clear signs of vascular and visceral injuries can avoid mandatory surgery. Instead high-resolution CT angiography was recommended to give detail about vascular, tracheal, and oesophageal injuries. CT without angiography can be used to rule out significant vascular injury if the trajectory is shown to be away from vascular structures (Figure 2) $[25,26]$.

In agreement with other studies done elsewhere, wound infection was the most common complication of treatment. Therefore, early and meticulous wound care should continue to be instituted in the management of penetrating neck injuries $[23,25]$.

The mean duration of hospital stay (6.6 days) in this study was found to be shorter than that reported by other authors 14 days (1-99 days) [20,24].

All the six deaths in this series were brought to the emergency room in profound hemorrhagic shock, unresponsive to verbal stimuli. Two of them were treated by immediate neck exploration, and the other four were resuscitated yet

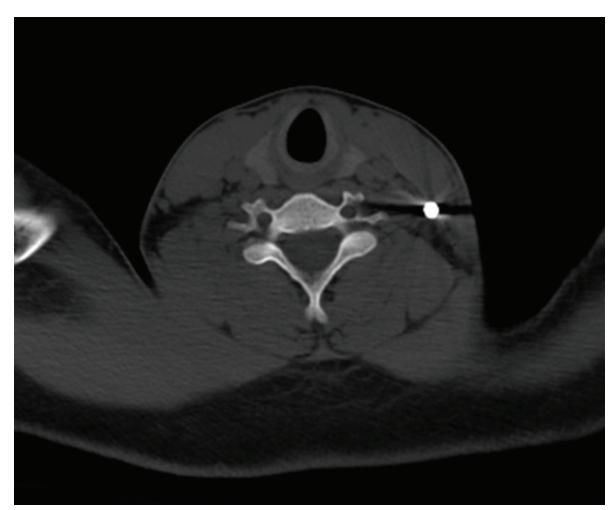

FIGURE 2: Coronal reformat CT scan revealed bullet injury in the neck with no injured neurovascular or aerodigestive structure.

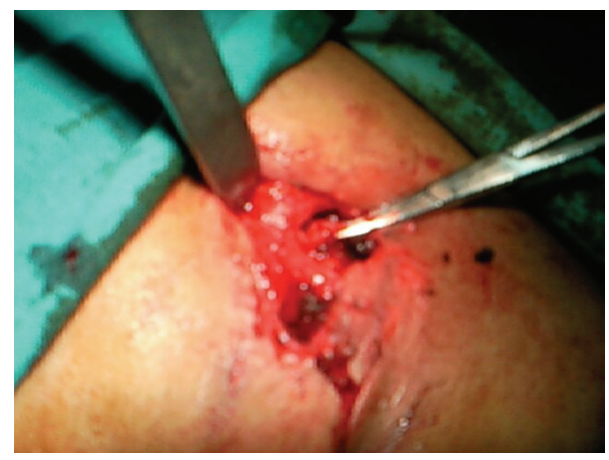

FIGURE 3: Intraoperative image of vascular ligature for one case with penetrating neck trauma following road traffic accident.

did not respond and died within 6 hours of admission. The deaths reflect the severity of injury and associated extracervical injuries. The mortality rate was $12.2 \%$ (6 cases); this is high compared to other papers, in which mortality rates ranged from 1.5 to $7.5 \%[1,7,13-16]$. The mean age of survivors was higher (32.2 years) than that of nonsurvivors (Table 3 ). This is due to road traffic accident being the leading cause of penetrating neck trauma so other confounding factors may have influenced this observation.

\section{Conclusion}

The present study illustrates the difficulties of managing penetrating neck injuries in our region Saudi Arabia. The incidence of penetrating neck injuries is high, but the severity of injury was mild in most of the cases. The findings of the study highlighted that injuries to the neck require a multidisciplinary approach, mandatory neck exploration is no longer considered acceptable, physical examination is probably the most useful diagnostic tool. Intervention should be directed to sites of possible injury, and noninvasive diagnostic modalities should be considered especially cervical CT. 


\section{References}

[1] J. L. Kendall, D. Anglin, and D. Demetriades, "Penetrating neck trauma," Emergency Medicine Clinics of North America, vol. 16, no. 1, pp. 85-105, 1998.

[2] B. Carducci, R. A. Lowe, and W. Dalsey, "Penetrating neck trauma: consensus and controversies," Annals of Emergency Medicine, vol. 15, no. 2, pp. 208-215, 1986.

[3] D. Demetriades, D. Theodorou, E. Cornwall et al., "Evaluation of penetrating injuries of the neck: prospective study of 223 patients," World Journal of Surgery, vol. 21, no. 1, pp. 41-48, 1997.

[4] R. P. Gonzalez, M. Falimirski, M. R. Holevar et al., "Penetrating zone II neck injury: does dynamic computed tomographic scan contribute to the diagnostic sensitivity of physical examination for surgically significant injury? A prospective blinded study," Journal of Trauma, vol. 54, no. 1, pp. 61-65, 2003.

[5] V. H. Gracias, P. M. Reilly, J. Philpott et al., "Computed tomography in the evaluation of penetrating neck trauma," Archives of Surgery, vol. 136, no. 11, pp. 1231-1235, 2001.

[6] W. L. Biffl, E. E. Moore, D. H. Rehse, P. J. Offner, R. J. Franciose, and J. M. Burch, "Selective management of penetrating neck trauma based on cervical level of injury," The American Journal of Surgery, vol. 174, no. 6, pp. 678-682, 1997.

[7] P. M. Rao, R. R. Ivatury, P. Sharma, A. T. Vinzons, Z. Nassoura, and W. M. Stahl, "Cervical vascular injuries: a trauma center experience,” Surgery, vol. 114, no. 3, pp. 527-531, 1993.

[8] H. V. Cabasares, "Selective surgical management of penetrating neck trauma. 15-Year experience in a community hospital," The American Surgeon, vol. 48, no. 7, pp. 355-358, 1982.

[9] M. A. Mansour, E. E. Moore, F. A. Moore, and T. A. Whitehill, "Validating the selective management of penetrating neck wounds," The American Journal of Surgery, vol. 162, no. 6, pp. 517-521, 1991.

[10] P. Vassiliu, J. Baker, S. Henderson, K. Alo, G. Velmahos, and D. Demetriades, "Aerodigestive Injuries of the Neck," The American Surgeon, vol. 67, no. 1, pp. 75-79, 2001.

[11] M. L. Klyachkin, M. Rohmiller, W. E. Charash, D. A. Sloan, and P. A. Kearney, "Penetrating injuries of the neck: selective management evolving," The American Surgeon, vol. 63, no. 2, pp. 189-194, 1997.

[12] L. R. Atteberry, J. W. Dennis, S. S. Menawat, and E. R. Frykberg, "Physical examination alone is safe for evaluation of vascular injuries in penetrating zone II neck trauma," Journal of the American College of Surgeons, vol. 179, no. 6, pp. 657$662,1994$.

[13] P. Insull, D. Adams, A. Segar, A. Ng, and I. Civil, "Is exploration mandatory in penetrating zone II neck injuries?" ANZ Journal of Surgery, vol. 77, no. 4, pp. 261-264, 2007.

[14] J. L. Lourenção, S. C. Nahas, N. F. Margarido, A. J. Rodrigues Junior, and D. Birolini, "Penetrating trauma of the neck: prospective study of 53 cases," Revista do Hospital das Clínicas, vol. 53, no. 5, pp. 234-241, 1998.

[15] M. Vaiman, I. Bekerman, and M. Puterman, "3D Computerassisted assessment of complicated penetrating foreign bodies cases in ENT practice," European Archives of Oto-RhinoLaryngology, vol. 266, no. 10, pp. 1599-1603, 2009.

[16] J. A. Asensio, C. P. Valenziano, R. E. Falcone, and J. D. Grosh, "Management of penetrating neck injuries: the controversy surrounding zone II injuries," Surgical Clinics of North America, vol. 71, no. 2, pp. 267-296, 1991.

[17] M. J. Martin, P. S. Mullenix, S. R. Steele et al., "Functional outcome after blunt and penetrating carotid artery injuries: analysis of the National Trauma Data Bank," Journal of Trauma, vol. 59, no. 4, pp. 860-864, 2005.

[18] J. P. Meyer, J. A. Barrett, J. J. Schuler, and D. Preston Flanigan, "Mandatory vs selective exploration for penetrating neck trauma: a prospective assessment," Archives of Surgery, vol. 122, no. 5, pp. 592-597, 1987.

[19] F. Obeid, G. Haddad, H. Hurst, and B. Bivins, "A critical reappraisal of mandatory exploration policy for penetrating wounds of the neck," Surgery Gynecology \& Obstetrics, vol. 160, pp. 517-522, 1985.

[20] P Gouleke, A. Goldstein, S. Sclafani, W. Mitchell, and G. Shaftan, "Routine versus selective exploration of penetrating neck injuries:randomized prospective study," The Journal of Trauma, vol. 24, pp. 1010-1014, 1984.

[21] R. Srinivasan, T. Haywood, B. Horwitz, R. F. Buckman, R. S. Fisher, and B. Krevsky, "Role of flexible endoscopy in the evaluation of possible esophageal trauma after penetrating injuries," The American Journal of Gastroenterology, vol. 95, no. 7, pp. 1725-1729, 2000.

[22] F. Múnera, J. A. Soto, D. M. Palacio et al., "Penetrating neck injuries: helical CT angiography for initial evaluation," Radiology, vol. 224, no. 2, pp. 366-372, 2002.

[23] J. Neto and R. Dedivitis, "Prognostic factors of penetrating neck trauma," Brazilian Journal of Otorhinolaryngology, vol. 77, no. 1, pp. 121-124, 2011.

[24] R. W. Nason, G. N. Assuras, P. R. Gray, J. Lipschitz, and C. M. Burns, "Penetrating neck injuries: analysis of experience from a canadian trauma centre," Canadian Journal of Surgery, vol. 44, no. 2, pp. 122-126, 2001.

[25] S. A. Tisherman, F. Bokhari, B. Collier et al., "Clinical practice guideline: penetrating zone II neck trauma," Journal of Trauma, vol. 64, no. 5, pp. 1392-1405, 2008.

[26] K. Inaba, F. Munera, M. McKenney et al., "Prospective evaluation of screening multislice helical computed tomographic angiography in the initial evaluation of penetrating neck injuries," Journal of Trauma, vol. 61, no. 1, pp. 144-149, 2006. 


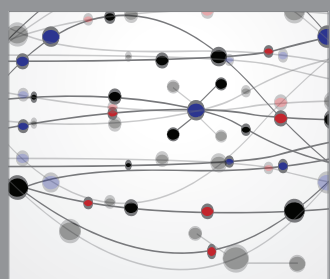

The Scientific World Journal
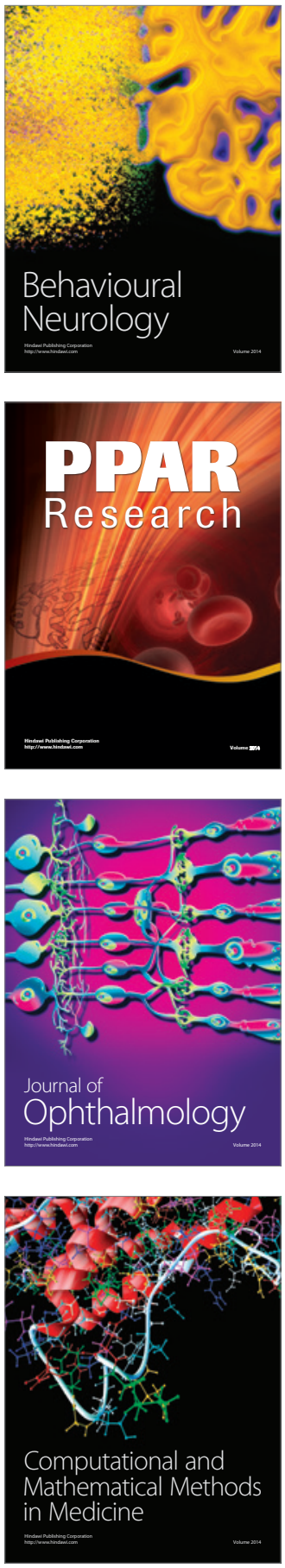

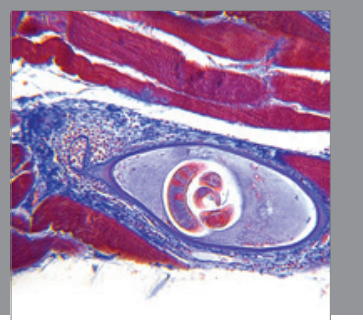

Gastroenterology

Research and Practice
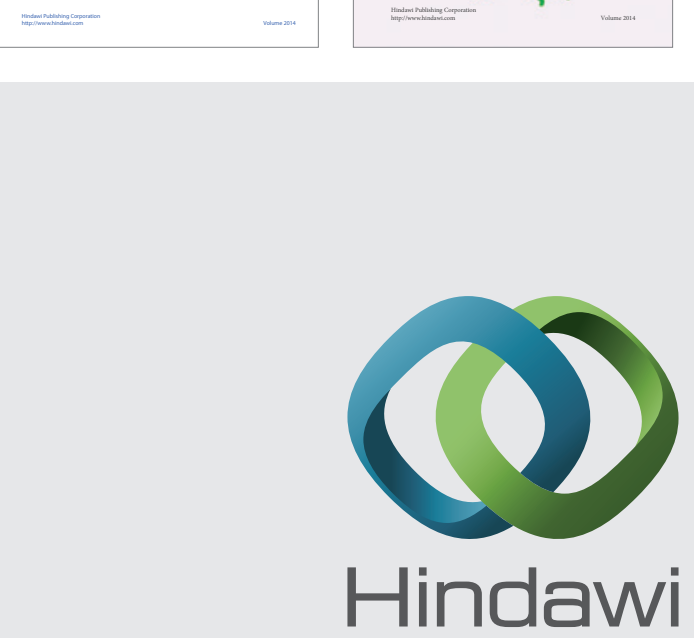

Submit your manuscripts at

http://www.hindawi.com
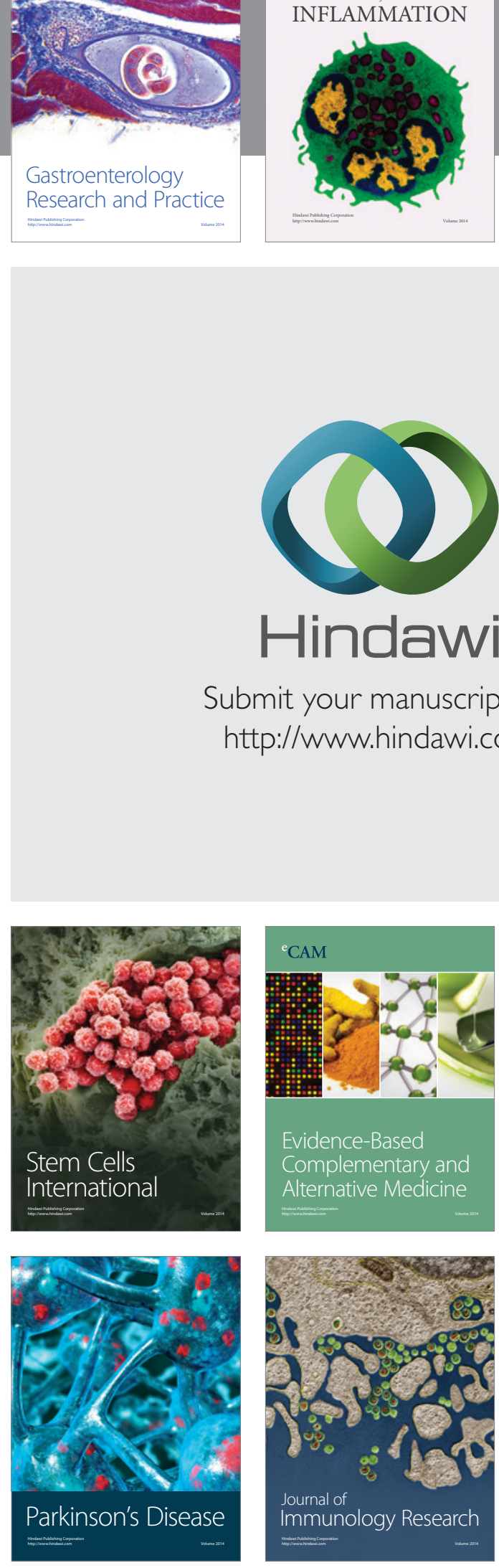

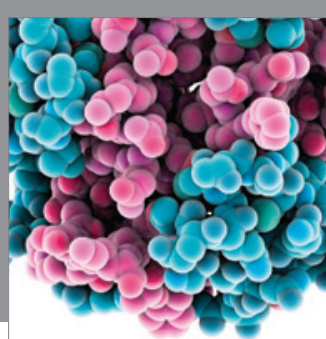

Diabetes Research
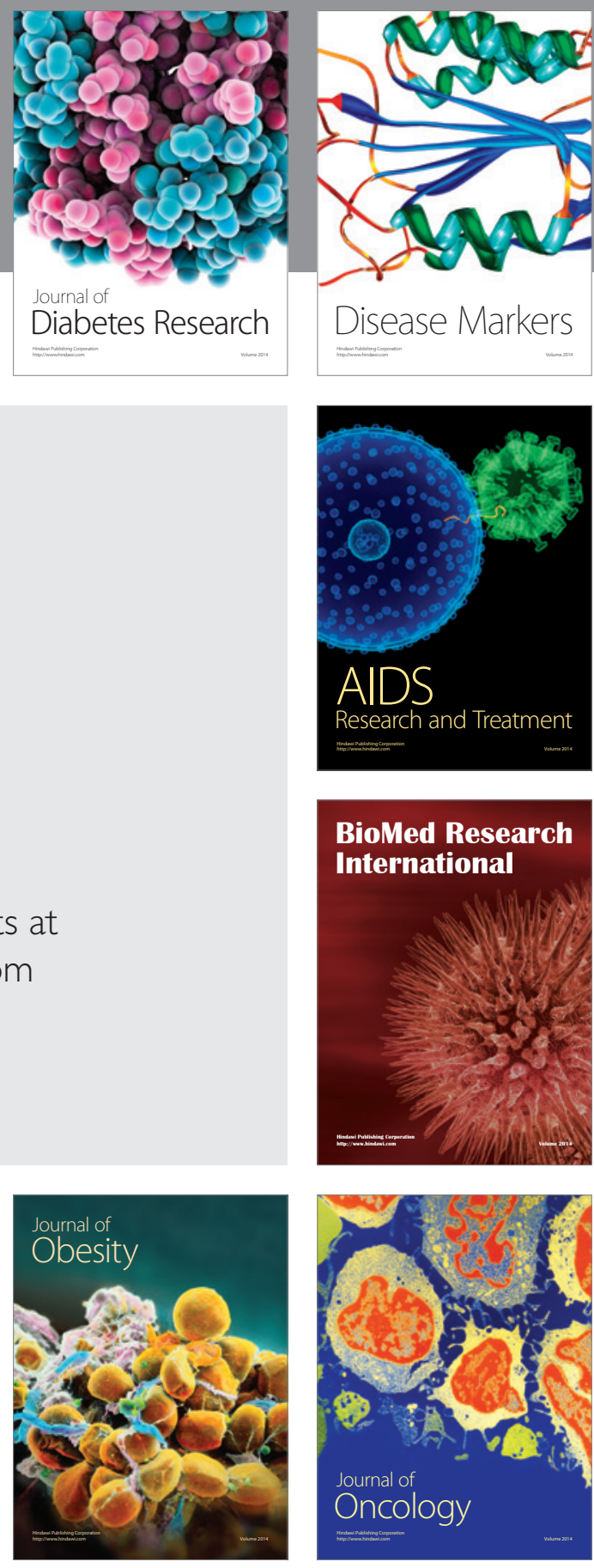

Disease Markers

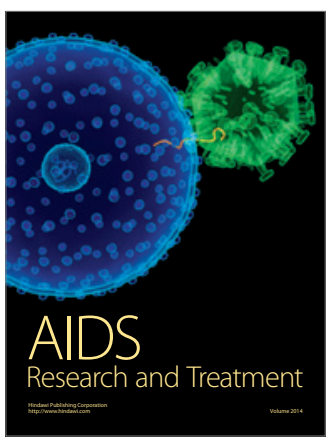

BioMed Research

International
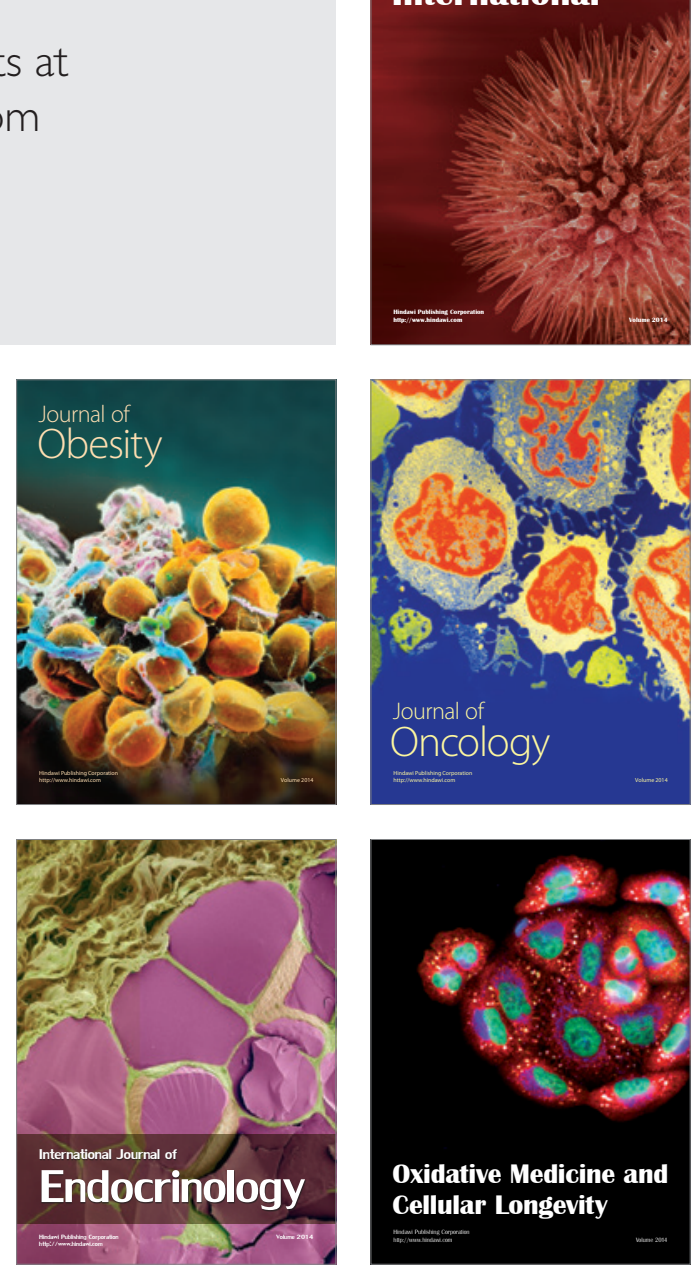